\title{
Research on Interpreting Volunteers Practice in Sports Events in Sichuan Ethnic Areas*
}

\author{
Ke Yang \\ Southwest Minzu University \\ Chengdu, China
}

\author{
Yunhui Bi \\ Honghe University \\ Honghe, China
}

\begin{abstract}
Sports events are an important part of China's sports industry, and interpreters are indispensable human resources in large-scale sports events. This paper analyzes and discusses the promotion effect of the participation of students from colleges for nationalities in the practice of interpreting volunteers on the progress of national unity by investigating the practice of students participating in interpreting of Southwest Minzu University, and puts forward some ideas to further improve the practice of interpretation, in order to better promote national unity in our multi-ethnic country.
\end{abstract}

Keywords—sports events; interpreting volunteers; practice; national unity

\section{INTRODUCTION}

With the increasing frequency of international exchanges and cooperation, all walks of life are facing the trend of globalization. Interpretation is increasingly important as a bridge to enhance understanding and strengthen communication [1]. As the number of large-scale sports events hosted by China has gradually increased and the scale has gradually expanded, as sports industry of new era of, the particularity of work and its own characteristics make volunteers a prominent feature of modern large-scale sports events [2]. In this context, students who are university language majors are more involved in the translation or interpreting volunteer service of sports events. As an important part of language teaching, the role of interpretation practice has received more and more attention.

We believe that the teaching of interpretation practice is not only an effective means to improve students' language application ability, but also enhances students' intercultural communication ability and cultural accomplishment. More importantly, in the volunteer activities of interpreters, volunteers from all ethnic groups have worked together and exchanged ideas, which have greatly promoted mutual understanding among various ethnic groups and have a good favor for national unity in multi-ethnic countries. In order to better understand the role of interpreting volunteers in the practice of national unity, in March 2018, the author conducted a questionnaire survey of students participating in

*Project information: this paper is a phased achievement of the general project of Sichuan National Education Development Research Center, a key research base of philosophy and social sciences in Sichuan Province universities. Project Name: Research on Interpretation Vocational Education in Sichuan Ethnic Areas. Project Number SEED201810. the volunteer activities of sports events in Southwest Minzu University to study students' participation of colleges for nationality in practice teaching of interpreting volunteers by analyzing the results of the survey and put forward some ideas to further improve the teaching of interpretation practice, so as to better promote national unity.

\section{SURVEY SitUATION ANALYSIS}

\section{A. Survey Respondent}

The students who participated in this survey were mainly university students of once participating in the volunteer activities of sports events in the Chengdu area, mainly from the Southwest Minzu University and they came from Han, Yi, Zhuang, Hui, Miao, Yao, Man, Mongolia, Tibet, Uygur, Tujia, Buyi, Dai, Bai and other ethnic groups. Among them, 35 people were Han students, accounting for $51.47 \%$ of the total number of participants, and 33 people were minority students, accounting for $48.53 \%$ of the total number of participants. The students who participated in the survey were mainly from southwestern minority areas such as Sichuan, Guizhou, Chongqing, Yunnan, and Tibet. Other students were from minority areas in Xinjiang, Ningxia, Inner Mongolia, and Jilin. The source and proportion of the survey sample can basically reflect the composition of the students in the national colleges and universities.

\section{B. Survey Content}

This survey consists of two parts: questionnaire survey and interview. Among them, the questionnaire has 15 choice questions, including four aspects: the attitude and status of participating in interpreting volunteer activities for sports events (1-5 questions, and one of them can be multiple); difficulties and differences of ethnic college students participating in interpreting volunteers activities (6-8 questions); the situation and content of interpreting volunteer activities for sports events (9-11 questions, 10th and 11th questions can be selected); evaluation of the practice teaching of interpreting volunteers and ethnic identity (12-15 questions). In addition, the author also interviewed two interpreting volunteers who participated in the 5th ChengduDubai International Cup Equestrian Festival, focusing on the situation and gains of students participating in the interpreting volunteer activities and the role of practice teaching of interpreting volunteers in the national unity of multi-ethnic countries. See the appendix for a sample of the questionnaire. 
The survey distributed questionnaires through the "wjx.cn" online platform, allowing the students to complete the questionnaire anonymously and freely. As of March 30, 2018 , a total of 68 valid questionnaires were collected. The data can be relatively true and reliable.

\section{Data Statistics}

After the answer sheets are completed, they will be collected for analysis and collation, and then the data will be quantitatively and qualitatively analyzed.

Taking the "choice" and "the number of people" of 68 questionnaires as variables, the data of the first 15 choice questions were statistically analyzed as follows ("Table I"):

TABLE I. The DATA OF THE FIRst 15 ChOICE Questions

\begin{tabular}{|c|c|c|c|c|c|c|c|c|c|c|c|c|c|c|c|}
\hline & 1 & 2 & 3 & 4 & 5 & 6 & 7 & 8 & 9 & 10 & 11 & 12 & 13 & 14 & 15 \\
\hline $\mathrm{A}$ & 36 & 58 & 3 & 50 & 59 & 9 & 14 & 8 & 33 & 28 & 37 & 6 & 10 & 31 & 26 \\
\hline B & 58 & 9 & 18 & 15 & 5 & 39 & 43 & 36 & 25 & 28 & 39 & 41 & 46 & 34 & 36 \\
\hline $\mathrm{C}$ & 51 & 1 & 37 & 3 & 4 & 12 & 8 & 19 & 10 & 24 & 44 & 17 & 12 & 0 & 6 \\
\hline $\mathrm{D}$ & 38 & & 10 & & & 8 & 3 & 5 & & 34 & 17 & 4 & 0 & 3 & \\
\hline $\mathrm{E}$ & 3 & & & & & & & & & 19 & & & & & \\
\hline
\end{tabular}

\section{Analysis and Discussion of Survey Results}

From the attitude of students participating in the interpreting volunteer activities for sports events, most students have a positive attitude towards participating in such activities. 58 of them expressed their willingness to participate actively and only one student clearly expressed dislike; for $73.53 \%$ of the students, it is considered that the practical teaching of interpreting volunteers is "very important" in their university curriculum; their participation in the activity is mainly for the purpose of improving their foreign language application ability and understanding more about the language and cultural differences of countries. There are also some students who are interested in sports itself. From the perspective of interpreting level, more than half of the students (37) think that their language skills are general and there is room for further improvement; 59 students think that such activities help to increase their confidence in interpreting learning and intend to further improve their interpreting skills.

In the questions concerning the difficulties and differences in the participation of ethnic college students in the activities of interpreting volunteers, most of the students (48 people) believe that the volunteer activities for interpreting in sports events are too demanding for students from ethnic minorities or from ethnic areas to complete the task. It is very difficult; most students (57 people) find that some thoughts and phenomena in Chinese and English are very different from those of local or national culture, causing students to have certain exchange difficulties with volunteer companions or foreign personnel in sports events; most students (44) strongly agree or basically agree that "ethnic minorities or students from minority areas have limited access to outside information from a young age, which affects their perception of other peoples and cultures".

Regarding the time of interpreting volunteer activities for sports events, most of the students ( 58 people) participated in the activities for less than one week; the responsible work content were logistics supports, accompanying interpretation, contact with foreign personnel and related document translation, etc.; the most contacted people in the activity were the volunteer companion (44 people choose), followed by the
Chinese staff (39 people choose) and the foreign participants (37 people choose).

From the evaluation of the practice teaching of interpreter volunteers, the majority of students (64) think that they have reached or partially met their expectations of participating in such activities; most of the students (56) are satisfied with the current practice teaching of interpreting volunteers; the vast majority of students (65) believe that participating in such activities makes them more intuitive to understand other countries' and nationals' culture, at the same time better understanding the national and ethnic culture of themselves.

In the interview, two students basically affirmed the role of participating in interpreting volunteers' activity for sports events in promoting national unity. They believed that participating in such activities "will enable everyone to better understand their own ethnic groups culture and other ethnic groups culture; can better understand tolerance and harmony", "can increase the enthusiasm of the nation and help strengthen the national cohesiveness", "can promote the communication, coexistence and integration of people among different ethnic groups", "can enhance the understanding of different ethnic groups and enhance the sense of honor and collectivity or sense of belonging of the nation; in addition, it prompts to recognize ethnic differences in practice, the connotation of national policies, and contribute to the unity and consolidation of multi-ethnic countries." For us, this kind of evaluation is also very happy to see.

Judging from the situation investigated by the author, the students who participated in the interpreting volunteer activities for the sports event came from many different ethnic groups. The student volunteers were able to contact interpreting service objects or counterparts volunteers from other countries during the work process at different levels, and can understand the differences with the language and culture of other countries and nations, thus strengthening the sense of identity with their own ethnics. It can be seen that participating in the interpreting volunteer activities is not only a process of language use, but also an excellent opportunity to communicate with peoples from other countries and nations. In the process of collaborating with volunteers from other ethnic groups, multi-ethnic culture exchanges can be achieved, 
which can promote the national unity of multi-ethnic countries.

\section{THOUGHTS ON IMPROVING THE TEACHING LINKS OF INTERPRETATION PRACTICE IN UNIVERSITIES FOR NATIONALITY}

\section{A. Difficulties in Students' Participation of Universities for Nationality in Interpretation Practice Activities}

First of all, ethnic college students are located in remote frontier areas where economic development is relatively lagging and the sources of information are relatively simple, which leads to their poor foreign language foundation, relatively weak language skills, and lack of understanding of other ethnic groups and cultures. Therefore, when they engage in interpreting volunteer activities, they often encounter the impact of other cultures, making it difficult to communicate with volunteer companions or foreign personnel in sports events.

Secondly, due to the lack of textbooks and practical design for interpreting teaching for ethnic college students, many ethnic college students do not understand their own language, and they have insufficient understanding of the history and culture of their own country and nation, so that they are inexplicable or unable to correctly convey the source language content when do Chinese-English interpreting, and encounter certain difficulties in promoting their ethnic culture.

\section{B. Suggestions on Improving the Teaching Links of Interpreting Practice of Universities for Nationality}

For the translation and interpretation difficulties of minority volunteers in colleges and universities for nationality, as teaching workers, it's necessary for them to innovate and improve the practice teaching of interpretation from the following ways.

1) Skill training: Most students feel that the main reason for their difficulties in interpreting is that they feel their interpreting ability poor, and afraid of mistakes in the process of interpreting. Especially for minority students, they feel that their ability to express themselves is insufficient, that they have practical opportunities to participate in international exchanges, and that they have less exposure to outside information, which is derived from the lack of proficient skill and exercise opportunities. Then, we can carry out basic tamping, skill training, and provide more information resources for volunteers with weaker foundations, so that they have more practical opportunities. In addition, students should be attached attention to the improvement of Chinese language learning and national culture, as well as the study of local and national languages and cultures, finally transforming the longterm influence of the fixed thinking styles brought about by their ethnic way of thinking and cognitive models.

2) Psychological diathesis improvement: Many volunteers, even if they are fully prepared, will have a nervous, unconfident mentality for various reasons, and even the phenomenon of fear and withdrawal will appear at the interpretation site. Then, improving their psychological quality has become a key point. The first is to encourage them to overcome psychological barriers, to psychologically guide them, and fundamentally, to increase the amount of excises and practice, so that they are more emboldened to do on-site interpretation.

3) Innovation of practice teaching mode: Practice is the sole criterion for testing truth. Focusing on practice, and learning in practice is the only way of practice teaching. For minority college students, it is necessary to grasp the relationship between commonality and individuality, and absorb more knowledge and information while accepting ordinary higher education. In addition, in practice, it's essential to make arrangements according to different situations, strive to give full play to the advantages of students, and provide them with more resources to make up for their own shortcomings through learning.

4) Focus of cultural background knowledge of interpretation: It is important to note that the cultural background knowledge contained in the interpretation is the learning content that students need to pay attention to. Therefore, in the process of college English interpretation teaching, teachers should guide students to fully understand the structural meaning of the text (including word meaning, sentence pattern and style of the article), grasp the author's true intentions and emotions, help students understand certain cultural background knowledge through film and television materials or text materials, thus enhancing students' ability to explain the original meaning of the source text through language symbols and their own cognition [3].

In addition, in the design of interpreting practice links in ethnic colleges and universities, we should take the actual situation of ethnic minorities or students from ethnic areas into consideration to increase the supply of information and resources, and further improve their language usage ability and interpretation level.

\section{CONCLUSION}

The work of language volunteers provides a good language environment for the competition event, and the quality of language service is one of the key factors for the success of the event [4]. Volunteers play an increasingly important role in the competition contest as China has successfully hosted the 2008 Beijing Olympic Games, the 2010 Guangzhou Asian Games, the 7th China City Games in 2011, and the 2012 Asian Youth Games. In particular, the number of volunteers from ethnic minorities has also increased year by year, and the Chinese compatriots of ethnic minorities have gradually entered the international arena.

This paper combines the investigation examples of interpreting volunteers of Southwest Minzu University who participated in sports events, and takes the role of interpreting volunteers in promoting national unity as an entry point to indicate that interpreters are important human resources for sports events. At the same time, starting from the practice of interpreting teaching in ethnic colleges and universities, this 
paper reveals the main problems in the practice of interpreting teaching in ethnic colleges and universities, and puts forward relevant coping strategies. In recent years, the sports events in Sichuan have flourished. Colleges and universities in Sichuan ethnic areas should seize this good opportunity to build an interpreting teaching model with the local characteristics, so that the interpreters in Sichuan national universities can show on the large-scale sports venues at home and abroad. Microscopically, it can not only effectively enhance the national sense of honor and collective sense of interpreters, but also enhance the popularity of interpreting teaching of Sichuan national universities in the field of higher education in China; from a macro perspective, it assists to promote and develop China's outstanding national culture globally and enhance the quality of China's large-scale sports events, thereby boosting China's competitiveness in the hosting and undertaking of large-scale sports events.

\section{REFERENCES}

[1] Hua Chao, Tian Chunyu, Su Yue. Research on Interpretation Application Skills in Large-scale Sports Events- - Review of Harbin's 24th Winter Universiade [J]. Economic Research Guide, 2010(2).

[2] Zhang Su. Research on Volunteer Training Model of Large-scale Sports Events[J].Natural Science,2017(7).

[3] Hu Xiaoqing. Research on Interpretation Teaching Innovation of College English under the Interpretive Theory [J]. Consumer Guide, 2016(7).

[4] Kui Liuqing, Wu Tianqi, Xia Yuling. Investigation on the Interpretation Service Quality of Language Volunteers in Nanjing Youth Olympic Games[J].Anhui Literature (The second half of the month), 2015(12). 